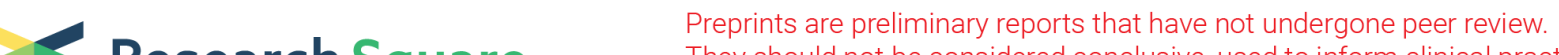 Research Square They should not be considered conclusive, used to inform clinical practice, or referenced by the media as validated information.
}

\section{Multicomponent Synthesis of 2, 4, 6-Triarylpyridine Analogues As Antibacterial And Antiurease Agents}

Muhammad Saleem

Ghazi University

Ayesha Perveen

University of Education Lahore

Erum Akbar Hussain

Lahore College for Women University

Abdul Rehman

Ghazi Khan Medical College

Majid Khan

University of Karachi

Misbah Irshad

University of Education Lahore

Muhammad Imran

King Khalid University

Ahmad Irfan

King Khalid University

Muhammad Ali

Gomal University

Shahiram Niaz

Gomal University

Abdur Rauf

University of Swabi

Mohammad S Mubarak ( $\square$ mmubarak@ju.edu.jo)

The University of Jordan https://orcid.org/0000-0002-9782-0835

\section{Research Article}

Keywords: 2,4,6-Triarylpyridine derivatives, Green synthesis, Anti-bacterial activity, Anti-urease inhibition, Density functional theory,

Posted Date: November 1st, 2021

DOI: https://doi.org/10.21203/rs.3.rs-1001428/v1 
License: (c) (i) This work is licensed under a Creative Commons Attribution 4.0 International License. Read Full License 


\section{Abstract}

Five new 2,4,6-triarylpyridine analogues with potential biological importance have been synthesized using the multicomponent reaction (MCR) solid support catalyst synthetic approach. This green synthesis furnished method simplicity, reduce reaction time, and excellent yield, along with an additional feature of catalyst reusability. A number of spectroscopic techniques such as ${ }^{1} \mathrm{H}-\mathrm{NMR}$, IR, and mass spectrometry, confirmed structures of the newly synthesized compounds. Antibacterial and anti-urease activities of these compounds were evaluated. Results revealed that compounds $\mathbf{4 a}, \mathbf{4 c}$, $\mathbf{4 d}$, and $\mathbf{4 e}$ exhibit significant inhibition against gram-positive bacterial pathogens. Furthermore, all synthesized compounds showed potent urease inhibitory activity with $\mathrm{IC}_{50}$ values ranging from $12.8 \pm 1.04$ to $23.7 \pm 0.23 \mu \mathrm{M}$ when compared with the standard inhibitor thiourea $\left(\mathrm{IC}_{50} 21.0 \pm 0.23 \mu \mathrm{M}\right)$.

In addition, the synthesized derivatives were subjected to density functional theory (DFT) calculations (DFT) to determine the energy of the molecules having biological potential.

\section{Introduction}

Microbial and viral infections continue to be a major health problem and a great challenge worldwide due to their potential resistance. Medicinal chemists have been persistently struggling to develop novel and effective antibiotics to overcome this problem (Mouradzadegun, Elahi, Ghanbarzadeh, Silicon, \& Elements, 2015). In this context, pyridine analogues have received considerable attention due to their unique structural features and diverse biological properties, which range from antibacterial, to antitumor (Ren \& Cai, 2009). Examples of such compounds that are marketed pharmaceuticals include esomeprazole, used to treat symptoms of gastroesophageal reflux disease (GERD), and can lower the risk of bleeding after endoscopy in patients with ulcers. Other examples include rimiterol and etoricoxb (Cotton et al., 2000). Rimiterol is a direct-acting sympathomimetic with predominantly $\beta$ adrenergic activity and a selective action on $\beta 2$-receptors; it is a third-generation short-acting $\beta \rrbracket$ agonist. Etoricoxb, on the other hand, is a selective inhibitor of cyclooxygenase-2 (COX-2), an enzyme involved in pain and inflammation, and is a nonsteroidal anti-inflammatory drugs (NSAIDs). Among other classes, 2,4,6-triarylpyridines are of great interest due to their wide range of biological and therapeutic potential.

Published research indicated that a large variety of catalysts such as heteropolyacid $\mathrm{H}_{14}\left[\mathrm{NaP}_{5} \mathrm{~W}_{30} \mathrm{O}_{110}\right]$, $\mathrm{Fe}_{3} \mathrm{O}_{4}$ supported silica sulfuric acid nanoparticles, $\mathrm{BaCl}_{2}$-nano $\mathrm{SiO}_{2}$, nano-ZnO powder, magnetic MIL101- $\mathrm{SO}_{3} \mathrm{H}$, heterogeneous silica vanadic acid $\left[\mathrm{SiO}_{2}-\mathrm{VO}(\mathrm{OH})_{2}\right]$, montmorillonite $\mathrm{K} 10$ clay, nanocrystals $\mathrm{MgAl}_{2} \mathrm{O}_{4}$, Brønsted-acidic ionic liquid $\left[\mathrm{HO}_{3} \mathrm{~S}\left(\mathrm{CH}_{2}\right)_{4} \mathrm{MIM}\right]\left[\mathrm{HSO}_{4}\right], \mathrm{PEG}_{1000}$ DAlL, acidified titanium silicates have been used in one-pot synthesis of 2,4,6-triarylpyridine analogues (Alinezhad, Tajbakhsh, \& Ghobadi, 2015; Boroujeni, Hashemzadeh, Faroughi, Shaabani, \& Amini, 2016; Davoodnia, Bakavoli, Moloudi, Tavakoli-Hoseini, \& Khashi, 2010; Gadekar \& Lande, 2018; Heravi, Bakhtiari, Daroogheha, \& Bamoharram, 2007; Kannan \& Sreekumar, 2013; Ren, Zhang, \& Jin, 2016; Reza, Shafiee, Moloudi, \& Ghashang, 2012; Safari, Gandomi-Ravandi, \& Borujeni, 2013; Shafiee \& Moloudi, 2011; Zolfigol et al., 2015). However, these 
syntheses suffer from a number of shortcomings including the use of expensive catalysts, and the removal of catalyst and additional purification steps, thus compromising green chemistry principles. Another challenge is to construct multifunctional structures with linear approach that suffers from overall low yield. To overcome these problems, the one-pot MCR approach has been adopted to afford structural complexity and diversity in a single step which is cost effective (Sunderhaus \& Martin, 2009). Accordingly, we have used the MCR method under solvent-free conditions, which is ecofriendly, and using a solid support silica impregnated with acid catalyst in the synthesis of new triarylpyridine analogues.

On the other hand, quantum chemical calculations are fascinating tools in chemistry as they rationalize the properties of newly synthesized compounds (A. J. C. m. s. Irfan, 2014). In this respect, the density functional theory (DFT) was comprehensively used to engross the geometric and electronic properties, which successfully reproduce experimental evidence (A. Irfan, Al-Sehemi, Chaudhry, \& Muhammad, 2018). In addition, it is a reliable tool for the ground state $\left(S_{0}\right)$ geometries and electronic properties (A. J. C. Irfan \& Chemistry, 2019; Lee, Yang, \& Parr, 1988). Similarly, B3LYP is rational for the $S_{0}$ geometries of various organic compounds (Preat, Jacquemin, Perpète, \& technology, 2010; Preat, Michaux, Jacquemin, \& Perpete, 2009). In the present study, optimizations were performed by B3LYP functional and triple zeta with 2 polarization function (TZ2P) basis sets. All calculations in this work were conducted using the Amsterdam Density Functional (ADF) modeling suite. Accordingly, we describe herein the synthesis and characterization of these new compounds (Schemes 1), along with the evaluation of their antibacterial and anti-urease activities. To the best of our knowledge, no previous study of this kind has appeared in the literature.

\section{Experimental}

\section{Materials and Methods}

All chemicals used throughout this investigation were purchased from Sigma Aldrich, Fluka and Merck, and were used as received. Progress of reaction and purity of products were monitored by thin layer chromatography (TLC) carried out on packed on silica gel Al (aluminum) sheets (60 F254). Plates were visualized under UV light, where appropriate. Catalyst was characterized by means of a scanning electron microscope (SEM), with accelerating voltage $0.2-30 \mathrm{kV}$ of $50 / 60 \mathrm{~Hz}$ power by (Carl Zeiss Company). Infrared (FTIR) spectra were recorded as $\mathrm{KBr}$ pellets in the range of $650-4000 \mathrm{~cm}^{-1}$ with a Shimadzu Corporation. ${ }^{1} \mathrm{H}$ NMR spectra of prepared compounds were recorded with the aid of a $500 \mathrm{MHz}$ spectrometer (AVANCE AV). Chemical shifts are reported in ppm using tetramethylsilane (TMS) as an internal standard and $\mathrm{CDCl}_{3}$ as solvent. ( ${ }^{1} \mathrm{H}$ NMR spectra of prepared compounds are displayed in Fig.

\section{S-Supplimentary).}

${ }^{1} \mathrm{H}$ NMR spectra of prepared compounds are displayed in the supplementary material.

\section{Catalyst preparation}


Catalyst was prepared according to a published procedure which involved stirring a mixture of conc. sulfuric acid and silica gel in dichloromethane for $4 \mathrm{~h}$; this has afforded a white amorphous powder, which was used as a solid support medium without further purification (Riego, Sedin, Zaldívar, Marziano, \& Tortato, 1996).

\section{General procedure for preparation of $4 a-e$}

Compounds $\mathbf{4 a - e}$ were prepared by the following procedure: Equimolar amounts of arylaldehydes (1ae), 2-acetylfuran (2), 2-acetylthiophene (3), $\mathrm{NH}_{4} \mathrm{OAc}$ (1.5 mole \%), and an appropriate amount of silica catalyst were mixed in a round bottom flask and refluxed at $80^{\circ} \mathrm{C}$ for $1 \mathrm{~h}$ (Table 1 ). Progress of reaction was monitored by TLC using (10\%) a mixture of $n$-hexane and ethyl acetate as a solvent system. Upon completion of reaction, the mixture was allowed to cool to room temperature, dissolved in methanol, and filtered. The filtrate was poured onto crushed ice to afford the final products $(\mathbf{4 a} \mathbf{a}-\mathbf{e})$. Using the same general procedure, the following compounds were prepared:

\section{2-(Furan-2-yl)-4-phenyl-6-(thiophen-2-yl) pyridine (4a)}

Prepared as light brown sticky solid, yield $60 \%$; $113^{\circ} \mathrm{C} ; \mathrm{R}_{\mathrm{f}}=0.72 \mathrm{~cm}^{-1} ; \mathrm{IR}(\mathrm{KBr}) \mathrm{cm}^{-1}: 1559$ (C=C), 1493 (C=N-C), 1235 (C-O-C), 1161 (C-S-C); ${ }^{1} \mathrm{H}-\mathrm{NMR}(500 \mathrm{MHz}, \mathrm{CDCl} 3) \delta$ (ppm): 7.85 (1H, d, J = $2.1 \mathrm{~Hz}, \mathrm{H}-3$ pyridyl), 7.82(1H, d, J=2.1 Hz, H-5 pyridyl), 7.62-7.78 (3H, m, Ar-H furfuryl), 7.40-7.32 (3H, m, Ar-H thienyl), 6.55-6.52 (5H, m, Ph),; MS m/z (ESI-MS) $304\left(\mathrm{M}^{+}\right)(90 \%)$.

\section{2-(2-(Furan-2-yl)-6-(thiophen-2-yl) pyridin-4-yl) phenol (4b)}

Dark brown, gummy solid; yield $65 \%$; mp $112^{\circ} \mathrm{C} ; \mathrm{R}_{\mathrm{f}}=0.846 \mathrm{~cm}^{-1}$; IR $(\mathrm{KBr}) \mathrm{cm}^{-1}: 1559$ (C=C), 1490 (C=NC), 1235 (C-O-C), 1157 (C-S-C); ${ }^{1} \mathrm{H}-\mathrm{NMR}(500 \mathrm{MHz}, \mathrm{CDCl} 3) \delta(\mathrm{ppm})$ :

$7.74(1 \mathrm{H}, \mathrm{d}, J=2.2 \mathrm{~Hz}, \mathrm{H}-3$ pyridyl) $7.63(1 \mathrm{H}, \mathrm{d}, J=2.3 \mathrm{~Hz}, \mathrm{H}-5$ pyridyl), 7.61-7.52 (3H, m, Ar-H furfuryl), 7.35-7.31 (3H, m, Ar-H thienyl) $6.99(1 \mathrm{H}, \mathrm{dd}, J=8.2,2.1 \mathrm{~Hz}, \mathrm{Ph} \mathrm{H}-3), 6.57(1 \mathrm{H}, \mathrm{ddd}, J=8.3,8.3,2.1 \mathrm{~Hz}, \mathrm{Ph}$ $\mathrm{H}-5), 6.55(1 \mathrm{H}, \mathrm{dd}, J=8.2,8.1 \mathrm{~Hz}, \mathrm{Ph} \mathrm{H}-4), 6.53(1 \mathrm{H}, \mathrm{dd}, J=8.2,2.1 \mathrm{~Hz}, \mathrm{Ph} \mathrm{H}-6)$. ; MS $m / z$ (ESI-MS) 320 $\left(\mathrm{M}^{+}\right)(90 \%)$.

\section{2-(Furan-2-yl)-4-(4-methoxyphenyl)-6-(thiophen-2-yl) pyridine (4c)}

Light brown, sticky solid; yield $63 \%$; M.P. $110^{\circ} \mathrm{C} ; \mathrm{R}_{\mathrm{f}}=0.57 \mathrm{~cm}^{-1}$; IR (KBr) cm${ }^{-1}: 1559$ (C=C), 1510 (C=N-C), 1243 (C-O-C), 1172 (C-S-C); ${ }^{1} \mathrm{H}-\mathrm{NMR}(500 \mathrm{MHz}, \mathrm{CDCl} 3) \delta$ (ppm): 7.85 (1H, d, J = 2.2 Hz, H-3 pyridyl), 7.83 $(1 \mathrm{H}, \mathrm{d}, J=2.2 \mathrm{~Hz}, \mathrm{H}-5$ pyridyl), 7.62-7.59 (3H, m, Ar-H furfuryl), 7.33-7.28 (3H, m, Ar-H thienyl), 7.15 (2H, $\mathrm{d}, J=8.2 \mathrm{~Hz}, \mathrm{H}-2$ and $\mathrm{H}-6), 6.92(2 \mathrm{H}, \mathrm{d}, J=8.2 \mathrm{~Hz}, \mathrm{H}-3$ and $\mathrm{H}-5), 3.86\left(3 \mathrm{H}, \mathrm{s}, \mathrm{OCH}_{3}\right) ; \mathrm{MS} m / z(E S I-M S) 334$ $\left(M^{+}\right)(100 \%)$. 
Dark brown, sticky solid; yield $60 \%$; M.P. $145^{\circ} \mathrm{C} ; \mathrm{R}_{\mathrm{f}}=0.57 \mathrm{~cm}^{-1}$; IR (KBr) cm${ }^{-1}: 1559$ (C=C), 1507 (C=N-C), 1237 (C-O-C), 1156 (C-S-C); ${ }^{1} \mathrm{H}-\mathrm{NMR}(500 \mathrm{MHz}, \mathrm{CDCl} 3) \delta$ (ppm): 7.62 (1H, d, J = 2.2 Hz, H-3 pyridyl), 7.60 $(1 \mathrm{H}, \mathrm{d}, J=2.2 \mathrm{~Hz}, \mathrm{H}-5$ pyridyl), 7.79-7.73 (3H, m, Ar-H furfuryl), 7.32-7.29 (3H, m, Ar-H thienyl), 6.966.70 (3H, m, Ar-H furfuryl); MS m/z (ESI-MS) $294\left(\mathrm{M}^{+}\right)(99 \%)$.

\section{4-(4-Chlorophenyl)-2-(furan-2-yl)-6-(thiophen-2-yl) pyridine (4e)}

Light brown, granular solid; yield $55 \%$; M.P. $120^{\circ} \mathrm{C}$; $\mathrm{R}_{\mathrm{f}}=0.65 \mathrm{~cm}^{-1}$; IR (KBr) cm${ }^{-1}: 1559$ (C=C), 1490 (C=NC), 1247 (C-O-C), 1163 (C-S-C); ${ }^{1} \mathrm{H}-\mathrm{NMR}(500 \mathrm{MHz}, \mathrm{CDCl} 3) \delta$ (ppm):

$7.81(1 \mathrm{H}, \mathrm{d}, J=2.2 \mathrm{~Hz}, \mathrm{H}-3$ pyridyl), $7.78(1 \mathrm{H}, \mathrm{d}, J=2.2 \mathrm{~Hz}, \mathrm{H}-5$ pyridyl), 7.64-7.57 (3H, m, Ar-H furfuryl), 7.42-7.35 (3H, m, Ar-H thienyl), $6.59(2 \mathrm{H}, \mathrm{d}, J=8.2 \mathrm{~Hz}, \mathrm{H}-3$ and $\mathrm{H}-5), 6.38(2 \mathrm{H}, \mathrm{d}, J=8.2 \mathrm{~Hz}, \mathrm{H}-2$ and $\mathrm{H}-6)$; MS $m / z$ (ESI-MS) $338\left(\mathrm{M}^{+}\right)(25 \%)$.

\section{Biological Activities}

\section{In Vitro Cytotoxicity Assay}

Cytotoxicity of the newly synthesized 2,4,6-triarylpyridine derivatives has been performed in 96-well microtiter plates using the 3-[4, 5-dimethylthiazole-2-yl]-2,5-diphenyl-tetrazolium bromide (MTT) colorimetric assay. In this assay, mouse fibroblast (3T3) cells were cultured in Dulbecco's Modified Eagle Medium, and mixed with $10 \%$ of fetal bovine serum (FBS), $100 \mathrm{IU} / \mathrm{mL}$ of penicillin, and $100 \mathrm{gg} / \mathrm{mL}$ of streptomycin in $75 \mathrm{~cm}^{2}$ flask. Flasks were then kept in an incubator with $5 \% \mathrm{CO}_{2}$ at $37^{\circ} \mathrm{C}$. Cultured cells with a concentration of 5,9 , and 104 cells $/ \mathrm{mL}$ were introduced $(100 \mu \mathrm{L} /$ well) into 96 well plates. After an incubation period of $12 \mathrm{~h}, 200 \mu \mathrm{L}$ of fresh medium was added with different concentrations of compounds $4 \mathrm{a}-\mathbf{e}(1 \mathrm{M})$. After 2 days, $200 \mu \mathrm{L}$ of MTT $(0.5 \mathrm{mg} / \mathrm{mL})$ was added to each well, and kept incubated for $4 \mathrm{~h}$. This was followed by addition of $100 \mu \mathrm{L}$ of DMSO to each well. The degree of reduction of MTT to form a zone within cells was measured at $540 \mathrm{~nm}$ using a microplate reader.

Cytotoxicity profile was calculated as the concentration causing $50 \%$ growth inhibition $\left(\mathrm{IC}_{50}\right)$ of $3 \mathrm{~T} 3$ cells (Saleem et al., 2016). The percent inhibition was calculated by using the following formula:

$$
\begin{aligned}
\% \text { inhibition } & =100-\frac{\text { mean of } O D \text { test }- \text { mean of } O D \text { of negative control }}{\text { mean of } O D \text { positive control }- \text { mean of negative control }} \\
& \times 100
\end{aligned}
$$

\section{Antibacterial Screening}

We evaluated the antibacterial activity of synthesized compounds $\mathbf{4 a}-\mathbf{e}$ using the disc diffusion method. Briefly, test compounds ( $10 \mathrm{mg} / \mathrm{mL}$ ) were applied on the pasteurized filter paper discs, dried overnight at room temperature, and stored; the negative control discs were prepared using the same procedure. In a standard microbiological working environment, bacterial cultures were grown overnight at $37^{\circ} \mathrm{C}$ in 
nutrient broth medium and spread onto solidified nutrient agar medium in petri dishes. Then control and test discs were applied onto the solidified medium surface and incubated at $37^{\circ} \mathrm{C}$ for $12-15 \mathrm{~h}$. Results were calculated by evaluating the zone of inhibition in millimeters for each compound and compared with sparaxin, used as a standard (Pervez et al., 2008).

\section{Urease Inhibition}

Investigation of the urease inhibition activity of compounds $\mathbf{4 a -} \mathbf{e}$ was carried according to the procedure outlined by Khan (2017) with slight modifications. Briefly, a total $200 \mu \mathrm{L}(0.5 \mathrm{mM})$ reaction mixture containing a $25-\mu \mathrm{L}$ urease enzyme solution was incubated for $15 \mathrm{~min}$ at $30{ }^{\circ} \mathrm{C}$. Then, $55 \mu \mathrm{L}$ of buffer and $100 \mathrm{mM}$ of substrate urea were incubated at the same conditions. After that, $0.5 \% \mathrm{w} / \mathrm{v}$ sodium hydroxide, $0.1 \%$ sodium hypochlorite $(70 \mu \mathrm{L}), 1 \% \mathrm{w} / \mathrm{v}$ phenol, and $0.005 \% \mathrm{w} / \mathrm{v}$ sodium nitroprusside $(45 \mu \mathrm{L})$ reagent were added and incubated at $30^{\circ} \mathrm{C}$ for $50 \mathrm{~min}$. To conclude the urease inhibition activity, ammonia production was measured by the indophenol method. Optical density (OD) measurements were conducted at $630 \mathrm{~nm}$ with the aid of an ELISA plate reader (KHAN, 2017). In this assay, thiourea was used as a standard and the percentage of inhibition was calculated using the following formula:

$\%$ inhibition $=100+\frac{O D \text { test }}{O D \text { control }} \times 100$

\section{Results And Discussion}

\section{Chemistry}

To accomplish this task, the solid support acid catalyst has been prepared with silica gel and sulfuric acid. $\mathrm{Si}-\mathrm{H}_{2} \mathrm{SO}_{4}$ catalyst was confirmed by the strong absorption band at $1060 \mathrm{~cm}^{-1}$, assigned to the transverse optic (TO) and longitudinal optic (LO) modes of Si-O-Si asymmetric stretching vibrations in the FTIR spectra as depicted in Fig. 1S and 2S (images available in supplementary material) (Musić, Filipović-Vinceković, \& Sekovanić, 2011). The surface morphology and texture of $\mathrm{Si}_{2} \mathrm{H}_{2} \mathrm{SO}_{4}$ catalyst was examined by scanning electron microscopic (SEM) images. Pure silica shows uniform crystalline form having same morphology throughout the texture whereas the $\mathrm{Si}_{2} \mathrm{H}_{2} \mathrm{SO}_{4}$ catalyst displayed inhomogeneity order of $\mathrm{SiO}_{2}$ crystals due to hydrogen bonding, and appeared with amorphous topology (supplementary material Fig. 3S and Fig. 4S). The $\mathrm{Si}_{2} \mathrm{H}_{2} \mathrm{SO}_{4}$ catalyst was successfully employed for the synthesis of five novels 2,4,6-triarylpyridine derivatives using various aryl-aldehydes $\left(R_{1}\right)$, and results are shown in Table 1.

Table 1. $\mathrm{Si}-\mathrm{H}_{2} \mathrm{SO}_{4}$ catalyzed synthesis of 2,4,6-triarylpyridine derivatives $4 \mathbf{a}-\mathbf{e}$ 


\begin{tabular}{|c|c|c|c|c|c|}
\hline Entry & Ar. & Products & Time (h) & Yield \% & M.P ${ }^{\circ} \mathrm{C}$ \\
\hline 1 & & $4 a$ & 1 & 60 & 113 \\
\hline 2 & & $4 b$ & 1 & 65 & 112 \\
\hline 3 & & $4 c$ & 1 & 63 & 110 \\
\hline 4 & & $4 d$ & 1 & 64 & 145 \\
\hline 5 & & $4 \mathrm{e}$ & 1 & 55 & 120 \\
\hline
\end{tabular}

\section{Proposed Mechanism involved in the synthesis of compounds $4 a-e$}

The proposed mechanism for the construction of 2,4,6,-triarylpyridine ring involved aldol condensation of 2-acetyl furan enol (I) with 2-acetyl thiophene to furnish a, $\beta$-unsaturated ketone (III) catalyzed by Si$\mathrm{H}_{2} \mathrm{SO}_{4}$. Then, activated thiophene enamine (V) was added to the double bond of (III) in a Micheal addition fashion to form (VI), which ultimately converts to its keto form (VII). This intermediate then undergoes hetroannulation by a nucleophilic attack of nitrogen on the carbonyl carbon to afford triaryl dihydropyridine (VIII), which upon oxidation yields the desired products (Fig. 1)

\section{Optimization of Reaction Conditions}

In order to find the optimum loading of catalyst, equimolar amounts of 2-acetyl furan, 2-acetyl thiophene, benzaldehyde, and $\mathrm{NH}_{4} \mathrm{OAc}(1.5$ mole \%) were mixed. In this regard, three parameters were explored for reaction optimization including catalyst ratio, catalyst amount, and temperature. Initially, several attempts were made with various ratios of $\mathrm{Si}_{2} \mathrm{H}_{2} \mathrm{SO}_{4}$ catalyst (Table 2). Results showed that the $\mathrm{Si}_{2} \mathrm{H}_{2} \mathrm{SO}_{4}$ catalyst with 1: 0.5 ratio proves an efficient catalyst, which led to a single spot on TLC for 2,4,6-triarylpyridines synthesis with minimum time as compared to other ratios.

Table 2. Comparison of different $\mathrm{Si}-\mathrm{H}_{2} \mathrm{SO}_{4}$ catalyst performance in model reaction 


\begin{tabular}{llll} 
Entry & $\begin{array}{l}\text { Ratio } \\
\mathrm{SiO}_{2}-\mathrm{H}_{2} \mathrm{SO}_{4}\end{array}$ & $\begin{array}{l}\text { Time } \\
(\mathrm{h}: \mathrm{min})\end{array}$ & $\%$ Yield \\
\hline 1 & $1: 0.25$ & 2 & 40 \\
\hline 2 & $1: 0.5$ & 1 & 60 \\
\hline 3 & $1: 0.75$ & $1: 30$ & 50 \\
\hline 4 & $1: 1$ & 3 & 30
\end{tabular}

Then, the effect of catalyst amount has been scrutinized, which revealed that with increased amount, reaction rate and product yields also increased. Results indicated that $1 \mathrm{~g}$ of the catalyst was sufficient for the target compound. However, $1.2 \mathrm{~g}$ decreased the product formation, which could be due to increased acidity of reaction system. Finally, the effect of temperature was investigated by carrying out the same model reaction at different temperatures, where good t yield obtained at $80^{\circ} \mathrm{C}$ (Table 3 ).

\section{Table 3. Effect of Temperature on product yield}

\begin{tabular}{lll}
$\mathrm{T}\left({ }^{\circ} \mathrm{C}\right)$ & Time $(\mathrm{h})$ & $\%$ yield \\
\hline 70 & 4 & 30 \\
\hline 75 & 3 & 45 \\
\hline 80 & 1 & 60 \\
\hline 85 & 1 & 40 \\
\hline 90 & 1 & 30
\end{tabular}

Finally, reusability of the catalyst is one of the most significant benefits of this strategy that makes the method cost effective. In this respect, the catalyst was filtered off, washed with water, dried, and reused for the same reaction. The catalyst could be recycled at least four times with only slight reduction in the catalyst activity.

Biological Activities

\section{In Vitro Cytotoxicity}

The synthesized derivatives, $4 \mathbf{a}-\mathbf{e}$, were evaluated for cytotoxicity assay against $3 T 3$ (mouse fibroblast) cell lines and exhibited $\mathrm{IC}_{50}>30$, suggesting they are non-cytotoxic. Experimental results were compared with the standard drug cyclohexamide with an $\mathrm{IC}_{50}$ value of $0.19 \pm 0.11 \mu \mathrm{M}$.

\section{Antibacterial Screening}


We evaluated the antibacterial activity of compounds $\mathbf{4 a - e}$ against four Gram-negative (Escherichia coli, Pseudomonas aeruginosa, Salmonella typhi, Shigella flexneri) and two Gram-positive (Bacillus subtilis, Staphylococcus aureus) bacterial strains. Results revealed that compounds $\mathbf{4 a}, \mathbf{4 c}$, $\mathbf{4 d}$, and $\mathbf{4 e}$ exhibit significant antibacterial activity against Gram-positive pathogens as shown in Table 4.

Table 4. Antibacterial activity of Triarylpyridine derivatives $4 a-e$

\begin{tabular}{lcccclll} 
& \multicolumn{3}{l}{ Gram-negative bacteria (\% inhibition) } & \multicolumn{2}{l}{ Gram-positive (\% inhibition) } \\
\cline { 2 - 7 } Compounds & E. coli & P. aeruginosa & S. typhi & S. flexneri & B. subtilis & S. aureus \\
\hline 4a & - & - & - & - & 78 & 68 \\
\hline 4b & - & - & - & - & - & - \\
\hline $\mathbf{4 c}$ & - & - & 9 & - & 5 & 46 \\
\hline $\mathbf{4 d}$ & - & 8 & 8 & - & 10 & 45 \\
\hline $\mathbf{4 e}$ & - & - & 3 & - & 8 & 62 \\
\hline Sparaxin & 92 & 93 & 93 & - & 94 & 90 \\
standard & & & & & &
\end{tabular}

\section{Urease Inhibition Activity}

Listed in Table 5 are the urease inhibitory activity of compounds $\mathbf{4 a - e}$. Results reveal that compound $\mathbf{4 a}$ exhibits potent urease inhibition with an $\mathrm{IC}_{50}$ value of $12.8 \pm 1.04 \mu \mathrm{M}$ when compared with the standard inhibitor, thiourea $\left(\mathrm{IC}_{50}=21.0 \pm 0.23 \mu \mathrm{M}\right)$. Results also show that compound 4a exhibits remarkable inhibition activity, and is more potent than the standard drug. This could be due to $\pi-\pi$ stacking interactions of the phenyl group at C-4 of the pyridine ring. Inhibition activity of compound $\mathbf{4 b}$ is lower than that of $4 \mathrm{a}$ with an $\mathrm{IC}_{50}$ of $19.6 \pm 1.68 \mu \mathrm{M}$; this might be due to the presence of an electron-donating group $(-\mathrm{OH})$ at the ortho position of phenyl ring bonded to $\mathrm{C}-4$. Similarly, compound $\mathbf{4 c}$ exerted significan inhibition with an $\mathrm{IC}_{50}$ of $15.8 \pm 2.23 \mu \mathrm{M}$, due to the methoxy group at the para position of phenyl moiety attached to $\mathrm{C}-4$ of the pyridine ring. On the other hand, the inhibition activity of compound $4 \mathbf{d}$ could be ascribed to the presence of hydrophilic interactions of furan and thiophene moieties. Furthermore, $\pi-\pi$ stacking interactions of the substituents may lead to the significant activity of compound $\mathbf{4 d}$, which has an $\mathrm{IC}_{50}$ value of $17.9 \pm 1.31 \mu \mathrm{M}$ as compared to standard. Finally, compound $4 \mathbf{e}$ was the least active as urease inhibitor with an $\mathrm{IC}_{50}$ of $23.7 \pm 0.23 \mu \mathrm{M}$; this may be due to decreased $\pi$ $\pi$ stacking interactions due to phenyl and chloro moieties.

Table 5. In-vitro urease inhibitory activity of triaryl pyridine derivatives 


\begin{tabular}{|c|c|c|c|}
\hline Compound & IUPAC Name & $\begin{array}{l}\% \\
\text { Inhibition }\end{array}$ & $\begin{array}{l}\mathrm{IC}_{50} \pm \mathrm{SEM} \\
{[\mu \mathrm{M}]}\end{array}$ \\
\hline $4 a$ & 2-(furan-2-yl)-4-phenyl-6-(thiophen-2-yl)pyridine & 87.9 & $12.8 \pm 1.04$ \\
\hline $4 b$ & 4-(2-(furan-2-yl)-6-(thiophen-2-yl)pyridine-4-yl)phenol & 90.3 & $19.6 \pm 1.68$ \\
\hline 4c & $\begin{array}{l}\text { 2-(furan-2-yl)-4-(4-methoxy phenyl)-6-(thiophen-2- } \\
\text { yl)pyridine }\end{array}$ & 88.9 & $15.8 \pm 2.23$ \\
\hline 4d & 2,4-di(furan-2-yl)-6-9(thiophen-2-yl)pyridine & 93.6 & $17.9 \pm 1.31$ \\
\hline $4 e$ & $\begin{array}{l}\text { 4-(4-chlorophenyl)-2-(furan-2-yl)-6-(thiophen-2- } \\
\text { yl)pyridine }\end{array}$ & 86.3 & $23.7 \pm 0.23$ \\
\hline Standard & Thiourea & 98.4 & $21.0 \pm 0.23$ \\
\hline
\end{tabular}

\section{Electronic Properties}

The frontier molecular orbitals (FMOs) including the highest occupied molecular orbitals (HOMOs and HOMOs-1) and lowest unoccupied molecular orbitals (LUMOs and LUMOs+1) of compounds $4 \mathbf{a}-\mathbf{e}$ at the B3LYP/TZ2P level are shown in Fig. 2. In $\mathbf{4 a}$ and $\mathbf{4 b}$, the spatial distribution of HOMO-1 is on thiophene and furan units along with the lone pair of electrons on the nitrogen atom of pyridine, HOMO and LUMO+1 at the 2-(furan-2-yl)-6-(thiophen-2-yl)pyridine moiety while the LUMO at 4-phenyl-6(thiophen-2-yl)pyridine. The intramolecular charge-transfer (ICT) was observed from HOMO-1 $\rightarrow$ LUMO as well as HOMO-1 $\rightarrow$ LUMO (furan to phenyl ring). In this respect, substitution of $-\mathrm{OH}$ at the $o$-position of phenyl (4b) has no significant effect on the FMOs charge density distribution, which is comparable to that of the parent compound $\mathbf{4 a}$. However, introduction of $-\mathrm{OCH}_{3}$ at the $p$-position of the phenyl group in 4c caused a significant effect on the FMOs, suggesting that HOMO-1 is delocalized at the methoxyphenyl-pyridine moiety, HOMO at 2-(furan-2-yl)-6-(thiophen-2-yl) pyridine, whereas the LUMO and LUMO+1 are localized at the thiophen-pyridine and furan-pyridine moieties, respectively.

In 4c, ICT was perceived from HOMO-1 $\rightarrow$ LUMO (methoxyphenyl to thiophene), HOMO-1 $\rightarrow$ LUMO+1 (methoxyphenyl to furan-pyridine), HOMO $\rightarrow$ LUMO (furan to thiophen-pyridine) and HOMO $\rightarrow$ LUMO+1 (thiophen to furan-pyridine). On the other hand, introduction of a furan ring to replace the phenyl group in $\mathbf{4 d}$ affected the spatial distribution of FMOs as compared to $\mathbf{4 a}$. The HOMO-1 is delocalized on 4-(furan-2yl)pyridine, HOMO at 2-(furan-2-yl)-6-(thiophen-2-yl)pyridin while LUMO is localized at 4-(furan-2yl)pyridine and LUMO+1 at 2-(furan-2-yl)-6-(thiophen-2-yl)pyridine. In 4d, ICT was perceived from HOMO$1 \rightarrow$ LUMO+1 (4-furan to thiophene and 2-furan), and HOMO $\rightarrow$ LUMO (thiophene and 2-furan to 4-furan). Substitution of the electron-withdrawing group $-\mathrm{Cl}$ at phenyl para position of parent compound furan ring in place of the phenyl in compound $\mathbf{4 e}$ has no significant effect on the spatial distribution of FMOs as compared to $\mathbf{4 a}$. The charge density distribution and ICT in $\mathbf{4 e}$ are almost similar to those of the parent compound. 
Energies of FMOs, i.e., HOMO-1 ( $\left.E_{\text {HOMO-1 }}\right)$, HOMO $\left(E_{\mathrm{HOMO}}\right)$, LUMO $\left(E_{\mathrm{LUMO}}\right)$, LUMO+1 $\left(\mathrm{E}_{\mathrm{LUMO}+1}\right)$, and HOMOLUMO energy gaps $\left(\mathrm{E}_{\text {gap }}\right)$ are important parameters in the electronic and photo-physical properties of organic compounds. The $\mathrm{E}_{\mathrm{HOMO}-1}, \mathrm{E}_{\mathrm{HOMO}}, \mathrm{E}_{\mathrm{LUMO}}, \mathrm{E}_{\mathrm{LUMO}+1}$, and $\mathrm{E}_{\text {gap }}$ of compounds $4 \mathrm{a}-\mathbf{e}$ at the B3LYP/TZ2P level at $S_{0}$ are listed in Table 7. Data show that $E_{\text {HOMO-1 }}$ at $S_{0}$ decreases in the order: $4 \mathbf{d}$ ($6.22)>\mathbf{4 b}(-6.27)=\mathbf{4 c}(-6.27)>\mathbf{4 c}(-6.37)>\mathbf{4 a}(-6.45)$. Similarly, data reveal that $\mathrm{E}_{\text {HOMO }}$ follows the order: $\mathbf{4 b}(-5.74)>\mathbf{4 e}(-5.84)>\mathbf{4 a}(-5.85)=\mathbf{4 d}(-5.85)>\mathbf{4 c}(-5.91)$, whereas the trend in the $\mathrm{E}_{\text {LUMO }}$ is: $\mathbf{4 b}(-1.55)>\mathbf{4 a}(-1.67)>\mathbf{4 c}(-1.69)>\mathbf{4 d}(-1.78)>\mathbf{4 e}(-1.82)$. In the meantime, $\mathrm{E}_{\mathrm{LUMO}+1}$ decreases in the following order: $\mathbf{4 b}(-1.39)>\mathbf{4 d}(-1.51)>\mathbf{4 a}(-1.52)>\mathbf{4 c}(-1.57)>\mathbf{4 e}(-1.64)$, whereas $\mathrm{E}_{\text {gap }}$ follows the order: $\mathbf{4 c}(4.22)>\mathbf{4 b}(4.19)=\mathbf{4 a}(4.18)>\mathbf{4 d}(4.07)>\mathbf{4 e}(4.02)$.

Shown in Table 7 are results pertaining to FMOs energies of compounds $4 \mathbf{4}-\mathbf{e}$. Results show that substituting the electron donating groups (EDG) $-\mathrm{OH}$ or $\mathrm{OCH}_{3}$ at the para position of phenyl increases $\mathrm{E}_{\text {HOMO-1. }}$. Similarly, replacing the 4-phenyl with 4-furan moiety in $\mathbf{4 d}$ increases $\mathrm{E}_{\text {HOMO-1. }}$. On the other hand, the EWG $-\mathrm{Cl}$ at the para position of the phenyl group decreases $\mathrm{E}_{\text {Hомо-1 }}$ as compared to $4 \mathrm{a}$, whereas The $\mathrm{EDG}-\mathrm{OH} / \mathrm{OCH}_{3}$ in $\mathbf{4 b}$ increases $\mathrm{E}_{\mathrm{HOMO}}$ as compared to the parent compound. Moreover, the EDG $-\mathrm{OH}$ in 4b increases $\mathrm{E}_{\mathrm{LUMO}}$ whereas $-\mathrm{OCH}_{3},-\mathrm{Cl}$, and 4-furan lower that term as compared to $4 \mathbf{a}$. In a similar fashion, the $-\mathrm{OH}$ in $\mathbf{4 b}$ increases $\mathrm{E}_{\mathrm{LUMO}+1}$ while $-\mathrm{OCH}_{3}$, and $-\mathrm{Cl}$ lower the values as compared to $\mathbf{4 a}$. Finally, the EDG $-\mathrm{OCH}_{3}$ causes an increase in $\mathrm{E}_{\text {gap }}$ while 4-furan and $-\mathrm{Cl}$ reduce its value as compared to compound $\mathbf{4 a}$.

Table 7. The ground state energies of FMOs; HOMO-1 ( $\left.E_{\text {HOMO-1 }}\right)$, HOMO ( $\left.E_{\text {HOMO }}\right)$, LUMO (E $\left.E_{\text {LUMO }}\right)$, LUMO+1 $\left(E_{\mathrm{LUMO}+1}\right)$, and $\mathrm{HOMO}-\mathrm{LUMO}$ energy gaps $\left(\mathrm{E}_{\text {gap }}\right)$ (in eV) of studied compounds.

\begin{tabular}{|llllll|}
\hline Compounds & $E_{\text {HOMO-1 }}$ & $E_{\text {HOMO }}$ & $E_{\text {LUMO }}$ & $E_{L U M O+1}$ & $E_{\text {gap }}$ \\
\hline 4a & & & & & \\
\hline 4b & -6.37 & -5.85 & -1.67 & -1.52 & 4.18 \\
\hline 4c & -6.27 & -5.74 & -1.55 & -1.39 & 4.19 \\
\hline 4d & -6.27 & -5.91 & -1.69 & -1.57 & 4.22 \\
\hline 4e & -6.22 & -5.85 & -1.78 & -1.51 & 4.07 \\
\hline
\end{tabular}

\section{Molecular Electrostatic Potential}

The Molecular electrostatic potential (MEP) explores the reactivity of various compounds and is measured experimentally by diffraction methods (Politzer \& Truhlar, 2013; Stewart, 1979) [23, 24] as well as by computational means. MEP illustrates the wide-ranging electronic and nuclear charge distribution, 
which is an appropriate feature to understand the reactivity of various species (Murray \& Politzer, 2011). Depicted in Fig. 3 is the MEP mapping of compounds $4 a-e$, illustrated in color visualizations. The red color denotes higher negative potential regions, which are required for electrophilic attack, whereas the blue color identifies the higher positive potential regions favorable for nucleophilic attack. In this respect, the MEP decreases in the order blue > green > yellow > orange > red; the red color shows the strongest repulsion while blue elucidates sufficient attraction.

In $4 \mathrm{a}$, the negative electrostatic potential is located on the oxygen of furan and nitrogen of pyridine, whereas the positive electrostatic potential is found on the phenyl and thiophene moieties. In $\mathbf{4 b}$, substituting the $-\mathrm{OH}$ at the ortho position of phenyl enhances the negative electrostatic potential at the entire molecule. Similarly, substituting the $-\mathrm{OCH}_{3}$ at the para position leads to negative electrostatic potential on oxygen of furan, nitrogen of pyridine, and oxygen of $-\mathrm{OCH}_{3}$, and positive electrostatic potential at phenyl and thiophene moieties in $\mathbf{4 c}$. On the other hand, the positive or negative electrostatic potentials in $\mathbf{4 d}$ and $\mathbf{4 e}$ are almost similar. These results reveal that in the case of a nucleophilic attack, significant repulsion would be at oxygen and nitrogen atoms in the furan and pyridine moieties, and on oxygen of $-\mathrm{OCH}_{3}$ in all studied compounds, except for $\mathbf{4 b}$ where most of the sites would behave as repulsion. The significant attraction would be thiophene and phenyl rings. It is also expected that in the case of an electrophilic attack, significant repulsion would be at the thiophene and phenyl rings whereas the noteworthy attraction would be at oxygen and nitrogen atoms in furan and pyridine, and on $-\mathrm{Cl}$ and oxygen of $-\mathrm{OCH}_{3}$.

\section{Hirshfeld Charges}

Shown in Fig. $\mathbf{3}$ are the Hirshfeld charges of the newly synthesized compounds $\mathbf{4 a}-\mathbf{e}$. Hirshfeld charges on various carbon, oxygen, nitrogen, and hydrogen atoms in the 2-(furan-2-yl)-6-(thiophen-2-

$\mathrm{yl}$ )pyridine moiety are almost similar in all of these derivatives. However, substituting the $-\mathrm{OH}$ or $-\mathrm{OCH}_{3}$ increases the positive charge of the carbon atom. The Hirshfeld charge on C2 was found -0.043 in $4 a$ while introducing the electron donating group (EDG) $-\mathrm{OH}$ lead to change the charge to 0.081 in $\mathbf{4 b}$. Similarly, Hirshfeld charge on $\mathrm{C} 4$ was -0.044 in 4 a while substituting with the $\mathrm{EDG}-\mathrm{OCH}_{3}$ lead to changing the value to 0.080 . The Hirshfeld charge on $\mathrm{C} 3$ was found -0.044 in 4 a while by introducing EDG $-\mathrm{OH}$ lead to change its charge -0.073 in $\mathbf{4 b}$. In addition, Hirshfeld charge on C3 was -0.044 in $4 a$ while by substituting EDG $-\mathrm{OCH}_{3}$ lead to change its value, i.e., -0.062 . The Hirshfeld charge on $\mathrm{C} 5$ was found -0.044 in $\mathbf{4 a}$ while by introducing $\mathrm{EDG}-\mathrm{OH} / \mathrm{OCH}_{3}$ lead to change its charge $-0.060 /-0.071$ in $\mathbf{4 b}$ / 4c, which is due to the donating effect of $-\mathrm{OH} / \mathrm{OCH}_{3}$. Replacing 4-phenyl by 4-furan moiety reduced the positive charge at $\mathrm{C} 7$ from 0.015 to 0.007 in $4 \mathrm{c}$. The electron-withdrawing group (EWG) $-\mathrm{Cl}$ at the para position of the phenyl group reduced the negative charge at C2, C3, C4, C5 and C6 atoms. However, the most significant effect was observed at $\mathrm{C} 4$ where the negative charge -0.044 has become 0.018 due to the withdrawing effect of $-\mathrm{Cl}$. The Hirshfeld charges revealed that $-\mathrm{OH}$ and $-\mathrm{OCH}_{3}$ at the ortho and para positions increase the negative charges on $\mathrm{C} 3$ and $\mathrm{C} 5$ atoms, suggesting that more negative charge on these sites in $\mathbf{4 b}$ and $\mathbf{4 c}$ would be favorable for electrophilic substitution. 


\section{Conclusions}

In summary, we have synthesized five new 2,4,6-triarylpyridine derivatives in good yield A using the solid support catalyst approach. The present methodology offered attractive features such as short reaction time, simplicity, and reusability of the catalyst. The prepared compounds were tested in vitro for antibacterial and urease inhibition activities. Results revealed that all of these newly synthesized compounds display good to moderate antibacterial and urease inhibition potential, and may serve as lead molecule in the drug discovery of new antibacterial drugs. In addition, the electronic properties of these derivatives have been determined with various methods such as DFT and Hirshfeld charges method.

\section{List Of Abbreviations}

$\left[\mathrm{SiO}_{2}-\mathrm{VO}(\mathrm{OH})_{2}\right]=$ Heterogeneous silica vanadic acid

$[$ TS-1] $=$ Titanium silicates

$[\mathrm{MTT}]=3$ - $[4,5$-dimethylthiazole-2-yl]-2, 5-diphenyl-tetrazolium bromide

[FBS] $=$ Fetal bovine serum

[EDG] $\quad=\quad$ Electron donating group

\section{Declarations}

\section{Acknowledgement}

The authors acknowledge the financial assistance of the Higher Education Commission (HEC) for funding under SRGP-HEC project No. 1394; this help is highly appreciated. Authors also highly acknowledge, the Husein Ebrahim Jamal Research Institute of Chemistry (HEJ) and the International Center for Chemical and Biological Sciences (ICCBS), University of Karachi, for providing spectroscopic techniques and biological studies of these compounds.

\section{References}

1. Irfan A, Al-Sehemi AG, Chaudhry AR, Muhammad S (2018) The structural, electro-optical, charge transport and nonlinear optical properties of oxazole (4z)-4-benzylidene-2-(4-methylphenyl)-1,3oxazol-5(4h)-one derivative. Journal of King Saud University - Science 30:75-82

2. Irfan A (2019) Comparison of mono- and di-substituted triphenylamine and carbazole based sensitizers @(tio2)38 cluster for dye-sensitized solar cells applications. Computational Theoretical Chemistry 1159:1-6 
3. Irfan A (2014) Modeling of efficient charge transfer materials of 4,6-di(thiophen-2-yl)pyrimidine derivatives. Quantum chemical investigations. Comp Mater Sci 81:488-492

4. Alinezhad H, Tajbakhsh M, Ghobadi N (2015) Nano-Fe304-supported, hydrogensulfate ionic liquidcatalyzed, one-pot synthesis of polysubstituted pyridines. Synth Commun 45(17):1964-1976

5. Boroujeni MB, Hashemzadeh A, Faroughi MT, Shaabani A, Amini MM (2016) Magnetic MIL-101-SO 3 $\mathrm{H}$ : a highly efficient bifunctional nanocatalyst for the synthesis of 1, 3, 5-triarylbenzenes and 2, 4, 6triaryl pyridines. RSC Advances 6(102):100195-100202

6. Lee $C$, Yang W, Parr RG. Development of the colle-salvetti correlation-energy formula into a functional of the electron density. Phys. Rev. B. 1988, 37, 785-789. b) A.D. Becke, Density-functional thermochemistry. III. The role of exact exchange. J. Chem. Phys. 1993, 98, 5648-5652

7. Cotton H, Elebring T, Larsson, Magnus, Li L, von Unge SH, Sverker, Asymmetric synthesis of esomeprazole, Tetrahedron: Asymmetry, 2000, 11(18), 3819-3825. b) Pinder, R.M., Brogden, R.N., Speight, T.M. et al. Rimiterol: A Review of its Pharmacological Properties and Therapeutic Efficacy in Asthma. Drugs, 2002, 14, 81-104. c) Deborah J. Cochrane, Blair Jarvis, Gillian M. Keating, Etoricoxib, Drugs, 1977, 62, 2637-2651

8. Davoodnia A, Bakavoli M, Moloudi R, Tavakoli-Hoseini N, Khashi M (2010) Highly efficient, one-pot, solvent-free synthesis of 2, 4, 6-triarylpyridines using a Brønsted-acidic ionic liquid as reusable catalyst. Monatshefte für Chemie-Chemical Monthly 141(8):867-870

9. Gadekar SP, Lande MK (2018) Solid acid catalyst TS-1 zeolite-assisted solvent-free one-pot synthesis of poly-substituted 2, 4, 6-triaryl-pyridines. Res Chem Intermed 44(5):3267-3278

10. Heravi MM, Bakhtiari K, Daroogheha Z, Bamoharram FF (2007) An efficient synthesis of 2, 4, 6triarylpyridines catalyzed by heteropolyacid under solvent-free conditions. Catal Commun 8(12):1991-1994

11. Kannan V, Sreekumar K (2013) Montmorillonite K10 clay catalyzed one pot synthesis of 2, 4, 6-tri substituted pyridine under solvent free condition. Modern Research in Catalysis 2(02):42

12. Khan M Identification of Urease Inhibitors, and Study of Their Effect on the Growth of Ureolytic Bacteria Responsible for Urotithiasis (Doctoral dissertation, HEJ Research Institute of Chemistry, International Center for Chemical and Biological Sciences) 2017

13. Mouradzadegun A, Elahi S, Ghanbarzadeh PA, Highly Efficient (2015) and Eco-Friendly Approach for the Synthesis of Triarylpyridine and Novel Triaryl-[1,3] Thiazepine Derivatives Via Ring Transformation and Expansion of Triarylthiopyrylium Salts. Phosphorus Sulfur Silicon the Related Elements 190(11):2031-2039

14. Murray JS, Politzer P (2011) The electrostatic potential: An overview, Wiley Interdisciplinary Reviews. Computational Molecular Science 1:153-163

15. Musić S, Filipović-Vinceković N, Sekovanić L (2011) Precipitation of amorphous $\mathrm{SiO}_{2}$ particles and their properties. Braz J Chem Eng 28(1):89-94

16. Pervez H, Iqbal MS, Tahir MY, Nasim FUH, Choudhary MI, Khan KM (2008) In vitro cytotoxic, antibacterial, antifungal and urease inhibitory activities of some N 4-substituted isatin-3- 
thiosemicarbazones. J Enzyme Inhib Med Chem 23(6):848-854

17. Politzer P, Truhlar DG (eds). Chemical applications of atomic and molecular electrostatic potentials. Plenum Press, 1981, New York

18. Preat J, Michaux C, Jacquemin D, Perpète E A. Enhanced efficiency of organic dye-sensitized solar cells: Triphenylamine derivatives. J. Phys. Chem. C. 2009, 113, 16821-16833. b) Frisch MJ, Trucks GW, Schlegel HB. Gaussian-09, revision a.1, gaussian, inc., wallingford, ct, in. 2009

19. Preat J, Jacquemin D, Perpète EA (2010) Design of new triphenylamine-sensitized solar cells: A theoretical approach. Environ Sci Technol 44:5666-5671

20. Ren YM, Cai C Three-component condensation catalyzed by molecular iodine for the synthesis of 2 , 4, 6-triarylpyridines and 5-unsubstituted-3, 4-dihydropyrimidin-2 (1H)-ones under solvent-free conditions. Monatshefte für Chemie-Chemical Monthly, 2009, 140(1), 49-52. b) Jones, D. H., Kay, S. T., McLellan, J. A., Kennedy, A. R., \& Tomkinson, N. C. Regioselective Three-Component Reaction of Pyridine N-Oxides, Acyl Chlorides, and Cyclic Ethers. Organic letters, 2017, 19(13), 3512-3515

21. Ren YM, Zhang Z, Jin S (2016) Convenient and efficient method for synthesis of 2, 4, 6triarylpyridines using catalytic amount of PEG1000-based dicationic acidic ionic liquid under solventfree conditions. Synth Commun 46(6):528-535

22. Reza M, Shafiee M, Moloudi R, Ghashang M (2012) ZnO nanopowder: an efficient catalyst for the preparation of 2, 4, 6-triaryl pyridines under solvent-free condition. APCBEE Procedia 1:221-225

23. Riego JM, Sedin Z, Zaldívar J, Marziano NC, Tortato C (1996) Sulfuric acid on silica-gel: an inexpensive catalyst for aromatic nitration. Tetrahedron Lett 37(4):513-516

24. Safari J, Gandomi-Ravandi S, Borujeni MB (2013) Green and solvent-free procedure for microwaveassisted synthesis of 2, 4, 6-triarylpyridines catalysed using $\mathrm{MgAl}_{2} \mathrm{O}_{4}$ nanocrystals. Journal of chemical sciences 125(5):1063-1070

25. Saleem M, Saeed A, Khan A, Abbasi S, Khan W, Khan SB (2016) \& Choudhary, M. I. Benzamide sulfonamide derivatives: potent inhibitors of carbonic anhydrase-Il. Med Chem Res 25(3):438-448

26. Shafiee MRM, Moloudi R (2011) Barium chloride dispersed on silica gel nanoparticles: an efficient catalyst for the preparation of 2, 4, 6-triarylpyridines under solvent-free conditions. J Chem Res 35(5):294

27. Stewart RF (1979) On the mapping of electrostatic properties from bragg diffraction data. Chem Phys Lett 65:335-342

28. Sunderhaus JD, Martin SF (2009) Applications of multicomponent reactions to the synthesis of diverse heterocyclic scaffolds. Chemistry - A European Journal 15(6):1300-1308

29. Zolfigol MA, Safaiee M, Afsharnadery F, Bahrami-Nejad N, Baghery S, Salehzadeh S, Maleki F (2015) Silica vanadic acid [SiO 2-VO $(\mathrm{OH})$ 2] as an efficient heterogeneous catalyst for the synthesis of 1, 2dihydro-1-aryl-3 H-naphth [1, 2-e][1, 3] oxazin-3-one and 2, 4, 6-triarylpyridine derivatives via anomeric based oxidation. RSC Advances 5(122):100546-100559

\section{Table}


The Table 6 is not available.

\section{Scheme}

Scheme 1 is available in the Supplementary Files section.

\section{Figures}
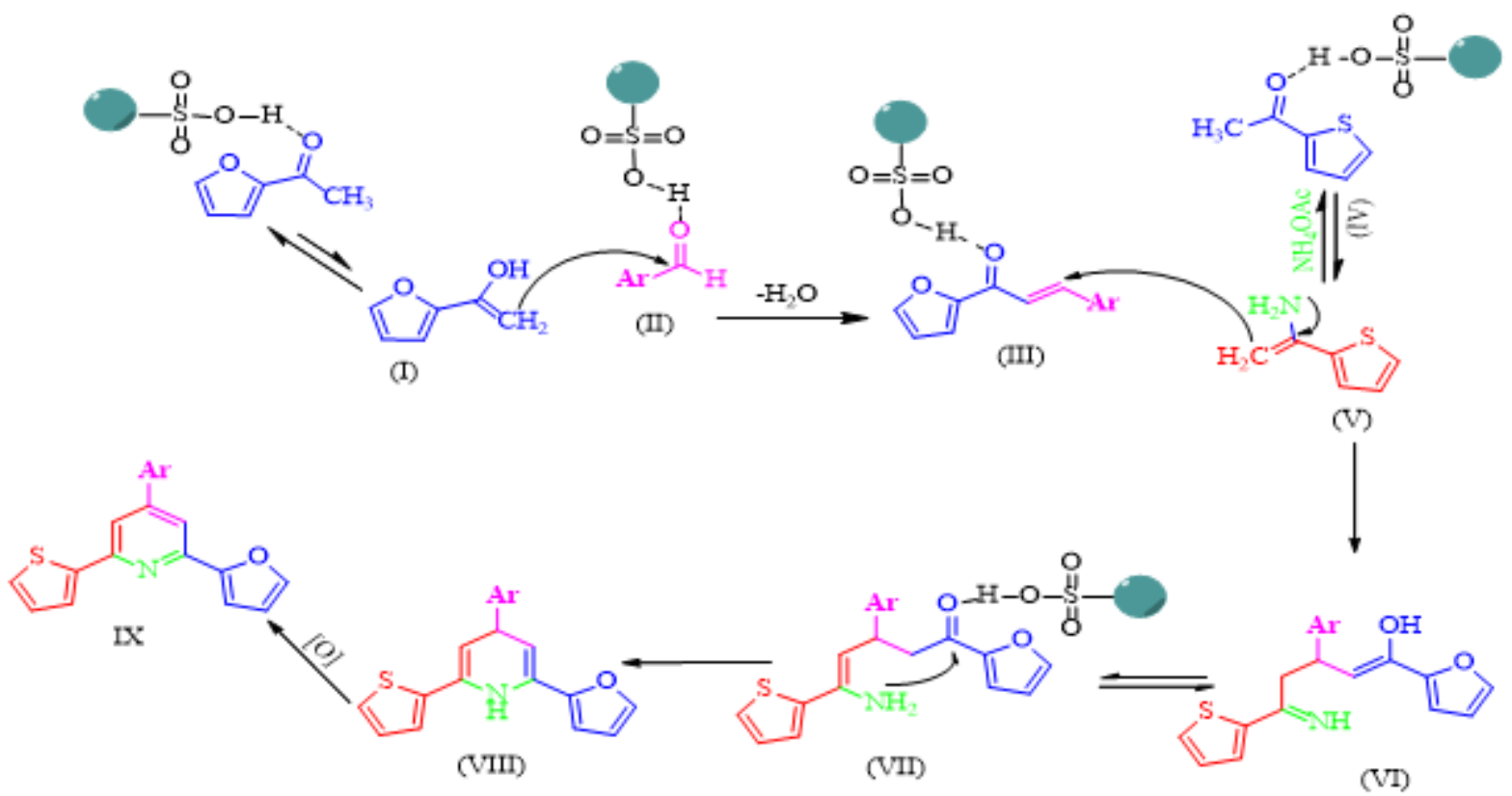

Figure 1

Proposed Mechanism for a one-pot Synthesis of 2,4,6-triarylpyridines 


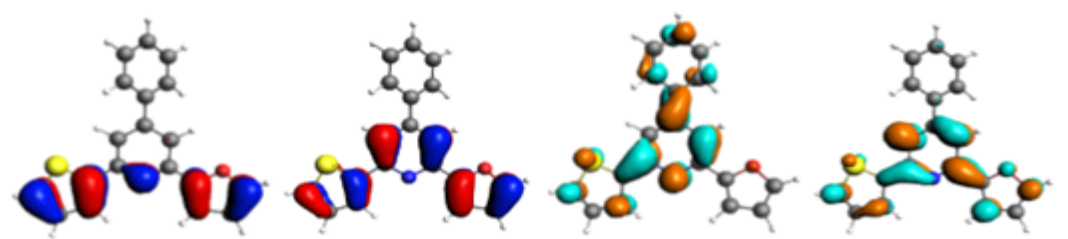

$4 a$

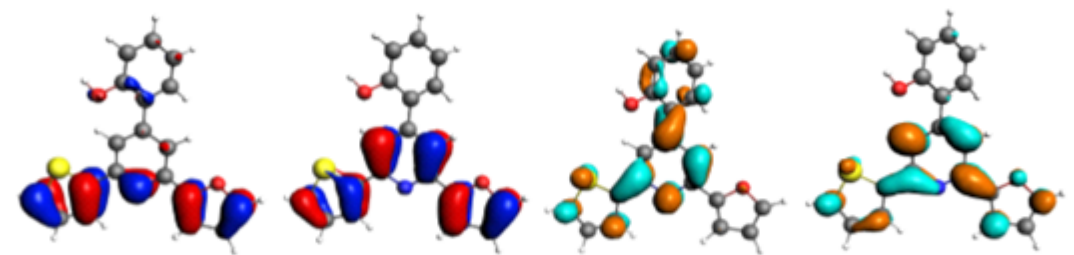

4b

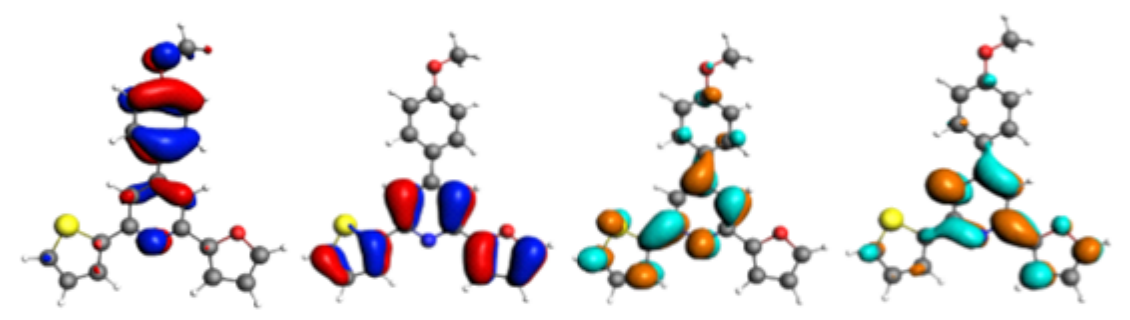

$4 c$

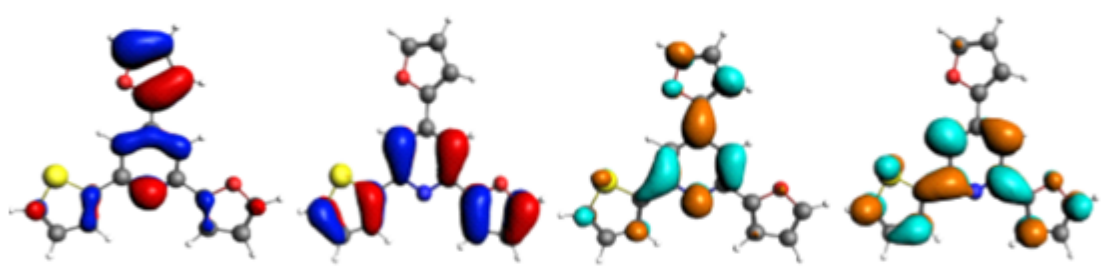

4d

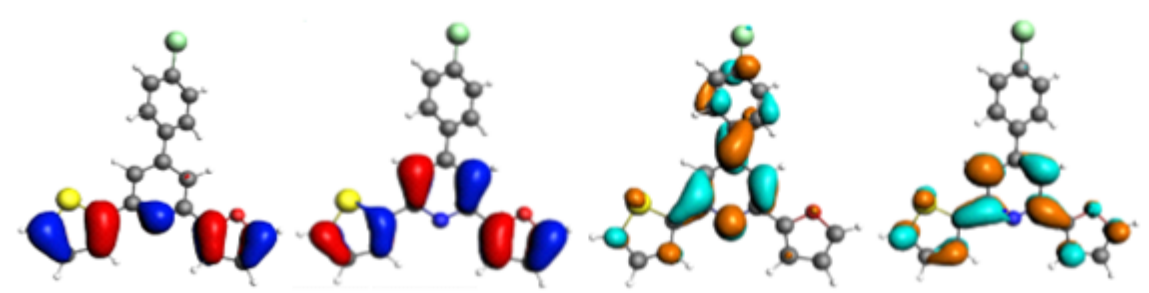

$4 e$

HOMO-1

HOMO

LUMO

LUMO+1

Figure 2

Ground state charge density of some frontier molecular orbitals (FMOs) of compounds $4 a-e$ (contour value $=0.035)$ 


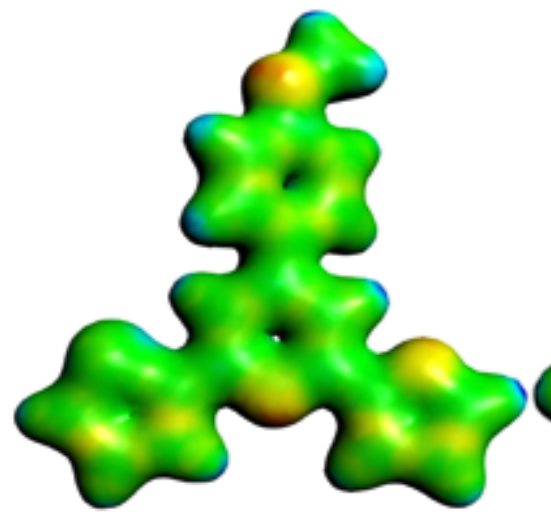

$4 c$

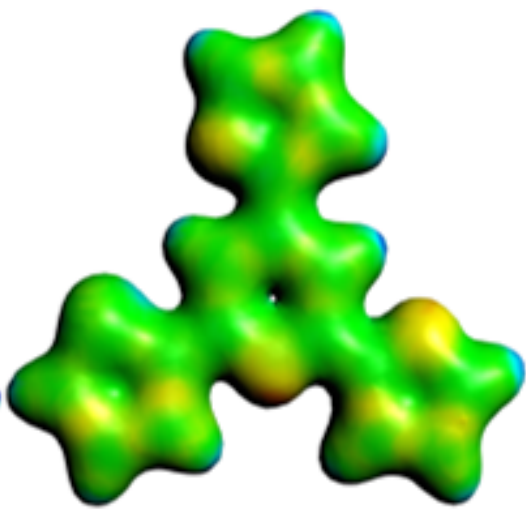

4d

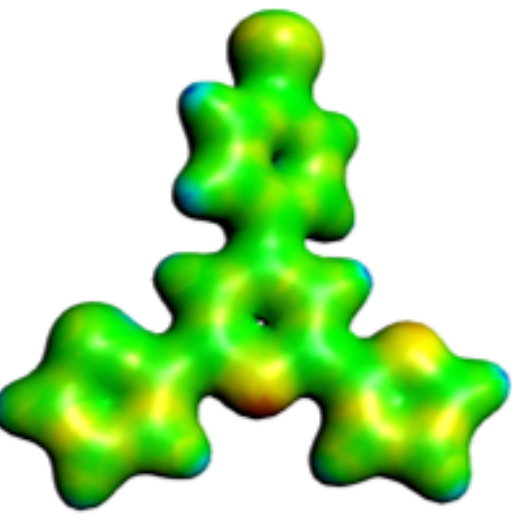

$4 e$

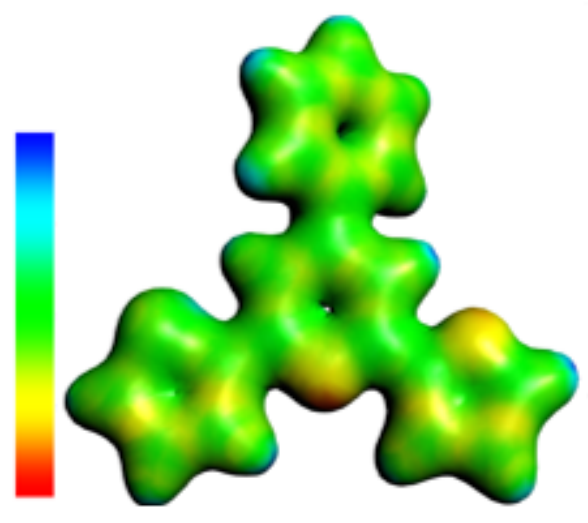

4a

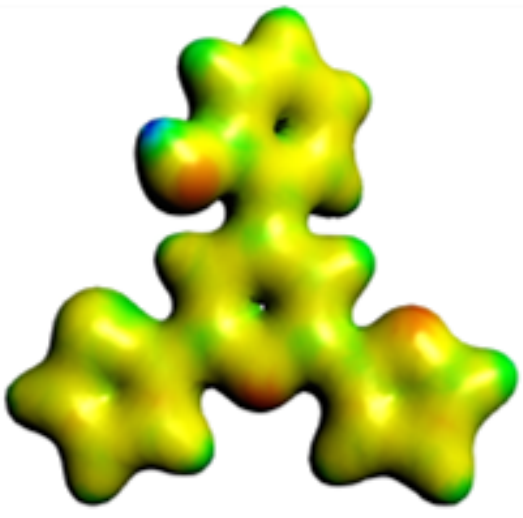

4b

Figure 3

Molecular electrostatic potential surfaces views of triarylpyridines 4a-e. 


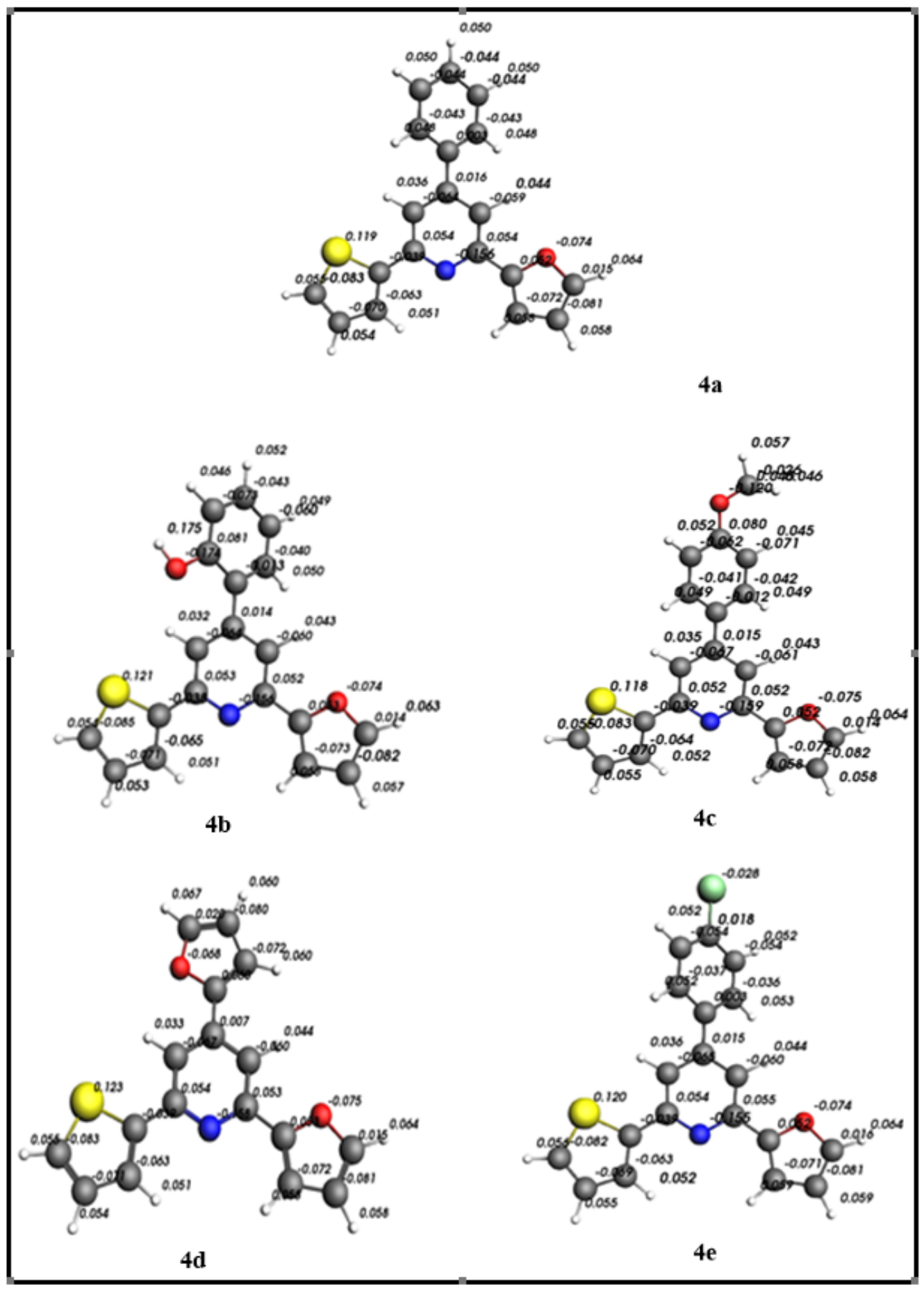

Figure 4

Hirshfeld charges of compounds 4a-e

\section{Supplementary Files}

This is a list of supplementary files associated with this preprint. Click to download. 
- Scheme1.png

- Supplymentrymaterial1.docx 